\title{
COMPREHENSIVE INTESTIGATION OF THE LIBERATION CHARACTERISTICS OF PYRITE AND OTHER MINERAL MATTER FROM COAL
}

\author{
Semi-Annual Technical Report \\ Reporting Period: 01/01/1998 - 06/30/1998 \\ Authors: Professor R. Peter King, Claudio Schneider \\ Report Issue Date: 07/30/1998 \\ DE-FG22-95PC95220 \\ University of Utah \\ Department of Metallurgical Engineering \\ 135 S 1460 E Rm 306 \\ Salt Lake City, Utah 84112
}




\section{DISCLAIMER}

This report was prepared as an account of work sponsored by an agency of the United States Government. Neither the United States Government nor any agency thereof, nor any of their employees, makes any warranty, express or implied, or assumes any legal liability or responsibility for the accuracy, completeness, or usefulness of any information, apparatus, product, or process disclosed, or represents that its use would not infringe privately owned rights. Reference herein to any specific commercial product, process, or service by trade name, trademark, manufacturer, or otherwise does not necessarily constitute or imply its endorsement, recommendation, or favoring by the United States Government or any agency thereof. The views and opinions of authors expressed herein do not necessarily state or reflect those of the United States Government or any agency thereof. 


\section{ABSTRACT}

The objective of this project is the development of methods for the measurement, prediction and modeling of the liberation characteristics of mineral matter and pyrite from coal, and to implement these findings in viable computer-simulation systems for coal cleaning plants. The central thrust of the project will be based on using the Andrews-Mika diagram as a convenient and experimentally verifiable model for the liberation characteristics of the constituents of coal during comminution. In order to establish the Andrews-Mika diagram, it is necessary to develop efficient techniques for density fractionation and for the measurement of the liberation spectrum in products obtained from the comminution of narrow composition fractions of coal. Dense-liquid techniques are used to produce fractionated samples, and image-analysis techniques, using linear-intercept analysis, are used to measure the liberation spectrum. The prediction of the liberation of mineral matter and pyrite from coal after comminution is based on a linear stochastic model for the description of the mineralogical texture and the random fracture pattern associated with the comminution process. Stereological correction of the distribution of linear grades is required for both the measurement and prediction of the true distribution of volumetric grades in the particle population. 
TABLE OF CONTENTS

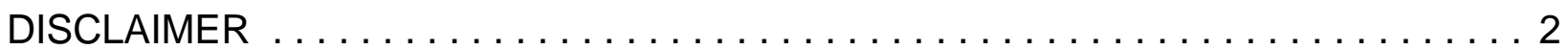

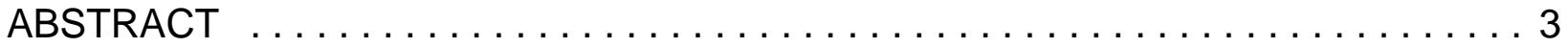

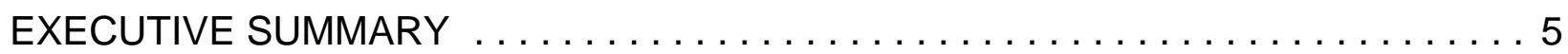

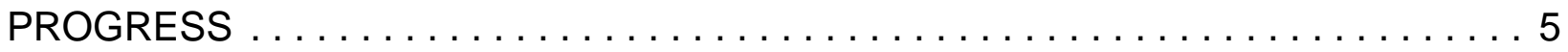

RESULTS AND DISCUSSION $\ldots \ldots \ldots \ldots \ldots \ldots \ldots \ldots \ldots \ldots \ldots \ldots \ldots \ldots \ldots$








\section{EXECUTIVE SUMMARY}

The objectives of the project are:

1. Develop laboratory and theoretical techniques for the quantitative measurement of the liberation spectra in samples of coal particles in the size range $50 \mu \mathrm{m}-1 \mathrm{~mm}$. Three dimensional spectra will be required to account for the mineral matter and pyrite separately.

2. Establish, experimentally, the Andrews-Mika diagram for a typical U.S. coal and to develop an appropriate parameterized description for the AndrewsMika diagram so that it may be determined easily and quickly for coals of different origin and different type.

3. Establish an effective and reliable simulation technique so that liberation of both pyritic sulfur and ash during comminution operations can be modeled and the operation of coal preparation facilities simulated. These models will be incorporated into a computer simulation system for coal cleaning plants.

The main conclusion from the work done prior to this reporting period is that the essential information required to predict and measure the liberation of ash and pyrite from coal during grinding can be measured using image analysis techniques. A successful stereological correction method for the ternary coal-ash-pyrite system has been developed and was reported previously.

During the previous reporting period, the fractionation of Pittsburgh \#8 coal was completed and the first controlled comminution of a monosize-monograde fractions undertaken.

Experimental work on this project was severely interrupted due to the breakdown of the SEM in October 1997. A new instrument was fully commissioned in May 1998 and intensive work since then has been undertaken to generate the required images from the samples of progeny particles that were collected during the controlled comminution experiment.

\section{PROGRESS}

The work undertaken on this project during the reporting period has been focused on the development of the complete Andrews-Mika diagram for the 3-component ash, pyrite, coal system. The Andrews-Mika diagram is essential to the development of an effective technique for the computation of the liberation of ash and pyrite from coal during industrial comminution operations. The approach used is to measure liberation spectra in each progeny size that results from the controlled breakage of monosize-mono-grade particles. A parameterized model of the Andrews-Mika diagram is then calibrated against the 
measured data.

A sample of raw Pittsburgh \#8 coal was obtained from Consol Inc. This material was crushed to less than $1 \mathrm{~mm}$. The $710 \times 1000 \mu \mathrm{m}$ fraction was carefully fractionated into 12 narrow density fractions and these fractions were subjected to controlled breakage. The properties of these parent and progeny particles were carefully measured and reported in the previous progress report.

During the current reporting period, work has been confined to the commissioning of a new SEM, its calibration for accurate size measurement and the collection of the large number of images required to characterize the liberation spectra of the progeny particles. By the end of the period 1500 images had been collected which is approximately $50 \%$ of the total number that will be required. The quality of the images has been good and it is anticipated that comparatively few repeat scans will be necessary.

Typical images of samples of the parent and progeny particles are shown in Figure 1. These images are consistent with the character of the coal that is expected from these samples. The image at top left shows the parent particles and the images of the progeny particles that result after controlled comminution are show at decreasing size. The liberation of both ash and pyrite becomes increasingly evident as the size of the progeny decreases. The data necessary to construct a model for the 3-component Andrews-Mika diagram will be available as soon as the image gathering phase is complete.

\section{RESULTS AND DISCUSSION}

A new scanning electron microscope has been purchased and commissioned to support the experimental requirements of this project.

The preparation of samples to characterize the ternary Andrews-Mika diagram has been completed.

All the images of the parent particles have been collected. Approximately $50 \%$ of the required number of images of progeny particles have been collected and it is anticipated that the remainder will be collected by mid-August 1998.

The theoretical work on the development of a model for the Andrews-Mika diagram has proceeded as far as possible without the necessary image analysis data. This development will be continued into the next reporting period. 

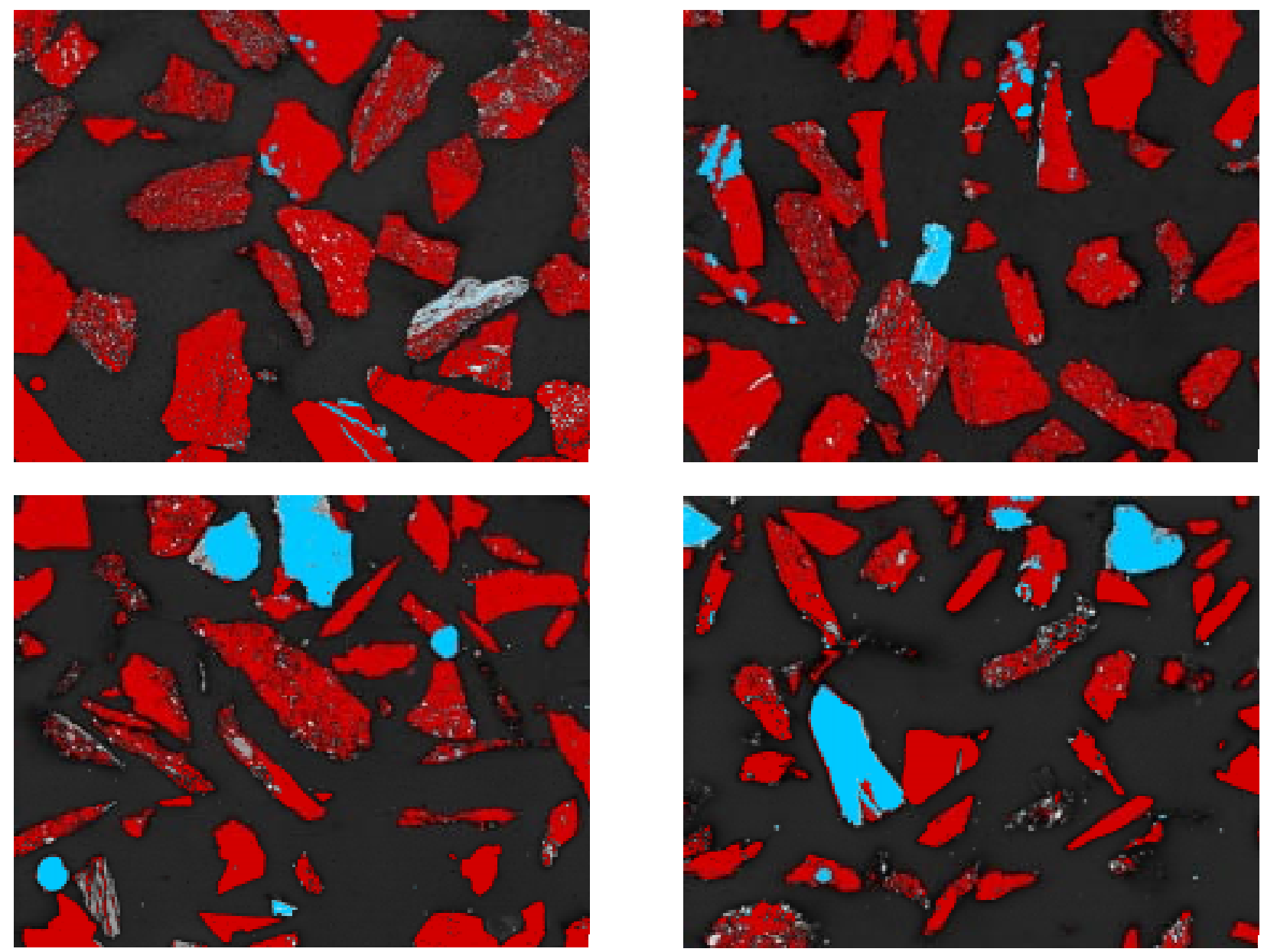

Figure 1 Backscattered electron images of coal particles. Top left is from fractionated particles in the $1.60 \times 1.37 \mathrm{~g} / \mathrm{cc}$ density range and $1000 \times 710$ micron size range. These particles were broken using a hammer mill, and a typical image of the progeny particles in the $355 \times 250$ (top right), 180x106 (bottom left) and 106×38 (bottom right) micron size ranges are shown.

\section{PERSONNEL}

Personnel who have contributed to this project during the reporting period are:

Professor R. P. King Principle Investigator

Dr. C. L. Schneider

Mr. Naiyang Ma

Postdoctoral Associate

Mz Heidi Petersen

PhD Student

Undergraduate Student 


\section{CONCLUSIONS}

1. Image collection on the parent and progeny particles from the controlled fracture tests on Pittsburgh \#8 coal has proceeded rapidly following the commissioning of a new SEM.

2. The images that have been collected so far indicate that they are suitable to undertake the required image analysis for the measurement of the liberation spectra and the subsequent generation of the 3-component Andrews-Mika diagrams..

\section{PUBLICATIONS}

Two major publications resulting from this project have been published during the reporting period.

King, R. P. and Schneider C. L., Stereological correction of linear grade distributions for mineral liberation. Powder technology 98, 21 -37 (1998)

King, R. P. and Schneider, C. L. Mineral Liberation and the Batch Comminution Equation Accepted for publication Minerals Engineering (1998) 